\title{
MRI Evaluation in Lumbar PIVD
}

\author{
Gurmeet Singh Sarla* \\ Classified Specialist Surgery, Military Hospital Devlali, India
}

Received: 㭗: September 25, 2018; Published: 啙: October 09, 2018

*Corresponding author: Gurmeet Singh Sarla, Classified Specialist Surgery, Military Hospital Devlali, Devlali Cantt, Nasik, Maharashtra, Pin 422401, India

\begin{abstract}
Degenerative disc disease of lumbar spine is almost universal with increasing age. Between 70-90\% of individuals will experience back pain at some point in their lives. The commonest site of pain in the spine is the intervertebral disc. Although the central part of the disc has no nerve supply, the annulus is very sensitive and is often a source of pain. Disc prolapse occurs commonly in middle age with a typical history of an episode of back pain either related to lifting and / or twisting or which occurs spontaneously. 80\% of disc prolapses occur in lumbar spine, the majority at L5-S1 and at L4-L5. The back pain commonly lasts for 2-6 weeks but is followed immediately by sciatica or nerve root pain. The pain follows one or more dermatomes and is often associated with neurological symptoms, altered sensation and weakness in the muscles innervated by the compressed nerve roots. Men are more commonly affected. Multiple level disc involvement is commoner as compared to single level disc involvement. L4-L5 and L5-S1 level discs are most commonly affected due to disc degeneration changes. MRI is the standard imaging modality for detecting disc pathology due to its advantage of lack of radiation, multiplanar imaging capability and precise localisation of intervertebral disc changes.
\end{abstract}

\section{Aims and Objectives}

The purpose of this study was to subject patients with persistent low backache who were unresponsive to 4 weeks of conservative management to imaging in the form of MRI Lumbo-Sacral spine and study the MRI findings and to evaluate the age and sex distribution and level and number of discs affected in degenerative lumbar disc disease by MRI.

\section{Materials and Methods}

In a peripheral hospital in Nasik, over a period of one year, a total number of 52 patients who presented with Low Backache unresponsive to conservative management for 4 weeks underwent MRI evaluation of the lumbar spine and the reports were analysed. The demographic details of the patients who reported to this hospital were extracted and the levels and number of the lumbar discs affected were classified according to their age and gender groups.

\section{Results}

Out of the 52 patients, 38 patients $(73.07 \%)$ were male and 14 patients (26.92\%) were female. The highest incidence, 22 patients (42.30\%) occurred in the age group of 30-40 years. Single disc involvement occurred in 14 patients (26.92\%). In 22 patients $(42.30 \%)$, discs were affected at two levels. In 18 patients (34.61\%), discs were involved at three levels. L4-L5 level disc was affected in 38 patients (73.07\%). An equal number of patients showed involvement of L5-S1 level disc (73.07\%). L3-L4 disc was involved in 22 patients (42.30\%). L2-L3 disc was involved in 8 patients (15.38\%). L1-L2 disc involvement occurred in 2 patients (3.84\%) (Figures 1-4).

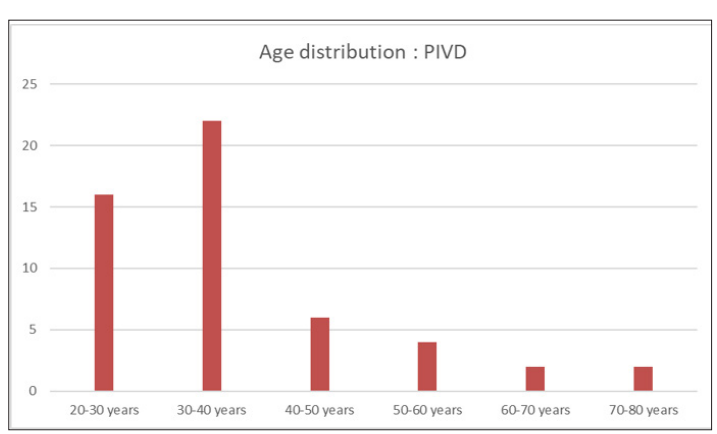

Figure 1: Age distribution: PIVD.

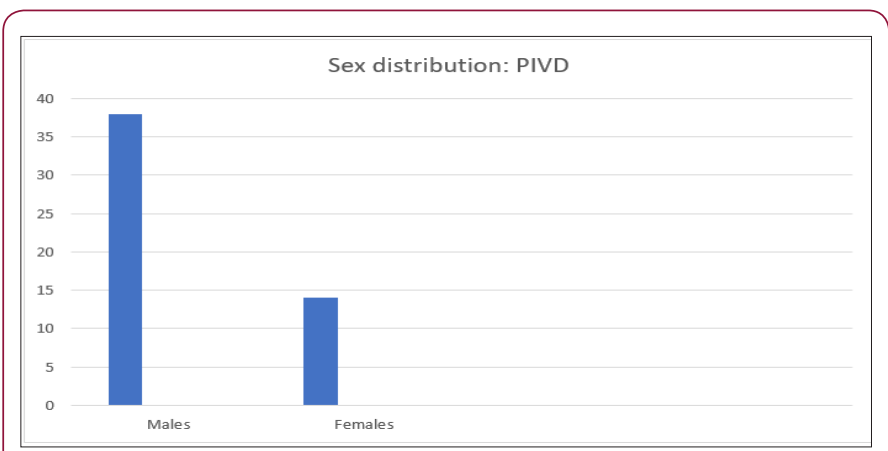

Figure 2: Sex distribution: PIVD. 


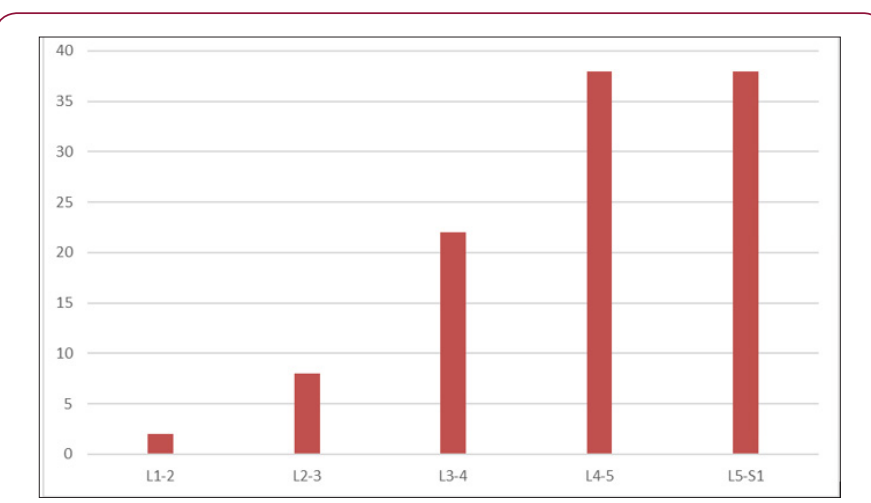

Figure 3: Disc level affected: PIVD.

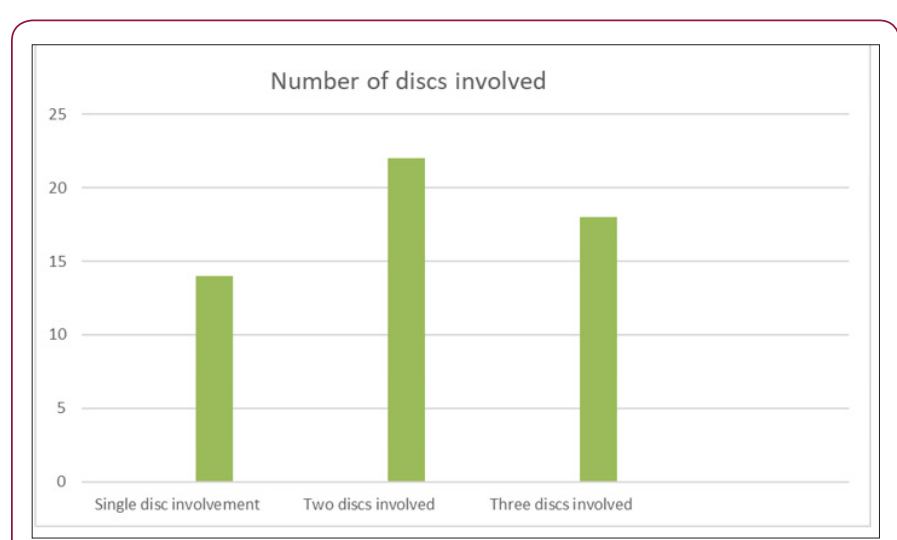

Figure 4: Number of discs involved.

\section{Conclusion}

Lumbar disc degeneration is the most common cause of low backache. Men are more commonly affected. Multiple level disc involvement is commoner as compared to single level disc involvement. L4-L5 and L5-S1 level discs are most commonly affected due to disc degeneration changes. X Ray LS spine with AP and Lateral views reveal gross anatomic changes in the intervertebral discs. MRI Lumbo-sacral spine is the standard imaging modality for detecting disc disease.

\section{Discussion}

Lower back pain secondary to degenerative disc disease is a condition that affects young to middle aged persons with peak incidence at the age of 40 years. The main symptom of disc degeneration after low back pain is sciatica. Sciatica is a sharp, shooting pain radiating to calf or sole of the foot which aggravates on standing, walking, bending, straining and coughing. There are many risk factors associated with lumbar degenerative disc disease like advancing age, smoking, obesity, trauma, heavy weight lifting, height and genetic factors [1]. Certain occupations like machine drivers, carpenters and office workers are associated with it [2]. Disc desiccation is a common degenerative change of intervertebral discs. It results from replacement of the glycosaminoglycans within the nucleus pulposus volume [3]. Disc degeneration with diffuse disc changes are more commonly found at L4-5 and L5-S1 level [4]. Multiplicity in the disc level involvement is common as compared to the single disc involvement [5] (Table 1).

Table 1: Neurological deficit in disc prolapse [8].

\begin{tabular}{|c|c|c|c|c|}
\hline Level & Nerve root affected & Motor weakness & Sensory loss \\
\hline L5-S1 & S1 root & $\begin{array}{c}\text { Weakness of planter flexors of the } \\
\text { foot }\end{array}$ & Over lateral side of foot \\
\hline L4-L5 & L5 root & $\begin{array}{c}\text { Weakness of EHL and dorsiflexors } \\
\text { of foot }\end{array}$ & $\begin{array}{c}\text { Over the dorsum of foot and } \\
\text { lateral side of leg }\end{array}$ \\
\hline L3-L4 & L4 root & Weakness of extensors of the knee & $\begin{array}{c}\text { Over great toe and medial side } \\
\text { of leg }\end{array}$ \\
\hline
\end{tabular}

The lower back pain and sciatica were due to nerve root compression, which was significantly associated with disc degeneration [6].Serious neurological symptoms may be an indication for urgent surgery to decompress the nerve roots but a waiting period is the best because $90 \%$ of patients will have relief of their pain within 6 weeks [7].Minor degrees of weakness and numbness will usually improve with time and may resolve completely [8]. Motor weakness is more likely to recover than sensory change [7]. Herniated lumbar disc is one of the most commonly diagnosed abnormalities associated with low backache [9]. Disc herniation of the same size may be asymptomatic in one patient and can lead to severe nerve root compromise in another patient [10]. MRI has emerged as an investigation of choice over other investigations for a herniated disc and become a gold standard to diagnose herniated disc [11]. Despite the high sensitivity of MRI, there is still a question about whether the modality is acceptably specific or not as sometimes it reveals abnormal findings in the absence of clinical signs and symptoms [12].

\section{References}

1. Battie MC, Videman T, Gibbons LE, Fisher LD, Manninen $H$, et al. (1995) Volvo Award in clinical sciences: determinants of lumbar disc degeneration-a study relating lifetime exposures and magnetic resonance imaging findings in identical twins. Spine 20(24): 2601-2612.

2. Saleem Shafaq, Aslam Hafiz Muhammad, Rehmani Muhammad Asim Khan, Raees Aisha, Alvi Arsalan Ahmad, et al. (2013) Lumbar Disc Degenerative Disease: Disc Degeneration Symptoms and Magnetic Resonance Image Findings. Asian Spine J 7(4): 322-334.

3. Lipson SJ, Muir H (1981) Experimental intervertebral disc degeneration: morphologic and proteoglycan changes over time. Arthritis Rheum 24(1): 12-21.

4. Cheung KM, Karppinen J, Chan D, Ho DW, Song YQ, et al. (2009) Prevalence and pattern of lumbar magnetic resonance imaging changes in a population study of one thousand forty-three individuals. Spine 34(9): 934-940.

5. Takatalo J, Karppinen J, Niinimäki J, Taimela S, Näyhä S, et al. (2009) Prevalence of degenerative imaging findings in lumbar magnetic resonance imaging among young adults. Spine 34(16): 1716-1721. 
6. Shambrook J, McNee P, Harris EC, Kim M, Sampson M, et al. (2011) Clinical presentation of low back pain and association with risk factors according to findings on magnetic resonance imaging. Pain 152(7): $1659-1665$.

7. RCG Russell, Norman S Williams, Christopher JK Bulstrode (Eds.) Bailey \& Love's Short Practice of Surgery: 520.

8. J Maheshwari, Vikram A Mhaskar (Eds.) Essential Orthopaedics: 201.

9. Frymoyer JW, Pope MH, Clements JH, Wilder DG, MacPherson B, et al. (1983) Risk factors in low-back pain. An epidemiological survey. J Bone Joint Surg Am 65(2): 213-218.

ISSN: 2574-1241

DOI: $10.26717 /$ BJSTR.2018.09.001848

Gurmeet Singh Sarla. Biomed J Sci \& Tech Res

(C) This work is licensed under Creative

Submission Link: https://biomedres.us/submit-manuscript.php
10. Modic MT, Ross JS (1991) Magnetic resonance imaging in the evaluation of low back pain. Orthop Clin North Am 22(2): 283-301.

11. Cranshaw C, Kean DM (1984) The use of unclear MR in diagnoses of lateral canal extra percent. J Bone Joint Surg Am 66B: 711-714.

12. Rothman RH (1984) A study of computer-assisted tomography. Spine9(6): 548 .

$\begin{array}{ll}\text { BIOMEDICAL } & \text { Assets of Publishing with us } \\ \text { RESEARCHES } & \text { Global archiving of articles } \\ \text { - Immediate, unrestricted online access }\end{array}$

